\title{
In-Vitro Antioxidant Capacity and Bioactive Compounds Preservation Post-Drying on Berrycacti (Myrtillocactus geometrizans)
}

\author{
Priscila D. Santiago-Mora ${ }^{1}$, Anaberta Cardador-Martínez ${ }^{1}$, Carmen Téllez-Pérez ${ }^{1}$, José Gerardo \\ Montejano-Gaitán $^{1} \&$ Sandra T. Martín del Campo ${ }^{1}$ \\ ${ }^{1}$ Escuela de Bioingenierías, Escuela Nacional de Ingeniería y Ciencias, Tecnológico de Monterrey, Campus \\ Querétaro, Querétaro, México \\ Correspondence: Sandra T. Martín del Campo, Escuela de Bioingenierías, Escuela Nacional de Ingeniería y \\ Ciencias, Tecnológico de Monterrey, Campus Querétaro, Epigmenio González 500, Fracc. San Pablo. Querétaro, \\ Querétaro, 76130, México. Tel: 52-442-238-3223. Email: smartinde@itesm.mx
}

Received: May 4, 2017 Accepted: May 31, $2017 \quad$ Online Published: June 30, 2017

doi:10.5539/jfr.v6n4p121 URL: https://doi.org/10.5539/jfr.v6n4p121

\begin{abstract}
Berrycactus is a cactus which does not require special agronomic attention, the berries are consumed locally and its commercialization is rather scarce because of the extremely short shelf-life. The significance of the application of any drying methods used to extend the shelf-life on the berrycacti is currently unknown. The aim of this work was to preserve berrycacti (Myrtillocactus geometrizans) and test the bioactive compounds and antioxidant capacity using two distinctive drying methods, freeze-drying (FD) and Instant Controlled Pressure Drop (DIC). Ripe berrycacti was chosen for the drying procedures because the antioxidant capacity and levels of soluble phenols and betalains were at their peak. Colour, phenols, non-extractable polyphenols, tannins, betalains, and antioxidant capacity were considered as factors to determine drying efficacy. Only colour parameters could discriminate between FD and DIC, concluding that both methods are suitable and efficient for preservation of antioxidant properties and retention of bioactive compounds. Both drying methods demonstrated higher in-vitro antioxidant capacity compared to the fresh fruit; highlighting the increase of non-extractable polyphenols and condensed tannins, and good retention of betalains and ascorbic acid after the drying treatments. This research points to use this sustainable crop to provide added value to berrycacti while considering this fruit as functional food due to the antioxidant capacity present even after being processed.
\end{abstract}

Keywords: antioxidant capacity, berrycactus, drying, freeze-drying, Instant Controlled Pressure Drop (DIC), ripening stages

\section{Introduction}

Myrtillocactus geometrizans (berrycactus) is a perennial Cactaceae plant native to Central Mexico, approximately $2.0 \mathrm{~m}$ tall with curved and thorny branches (Guzmán-Maldonado, Villordo, González-Chavira, Pons-Hernández, \& Hernández-López, 2012). The cactus has white flowers and produces dark purple berry like fruit with ellipsoid dimensions about $2.8 \mathrm{~cm}$ by $2.0 \mathrm{~cm}$ (Arias, 2010). These fruits have a very thin skin and the flesh is rich in color with gelatinous pulp and miniature black seeds (Herrera-Hernández, Guevara-Lara, Reynoso-Camacho, \& Guzmán-Maldonado, 2011). Myrtillocactus geometrizans grows in arid and semiarid regions and the cactus does not require special agronomic attention. The berries are consumed locally in rural areas (Perez-Gonzalez, 1995). Berrycactus commercialization is rather scarce because of the extremely short shelf-life, which is approximately 2 days at room temperature and 5 days under refrigeration (Hernández-López, Vaillant, Reynoso-Camacho, \& Guzman-Maldonado, 2008). The significance of the application of any drying methods used to extend the shelf-life on the berrycacti is currently unknown.

Berrycactus fruit contains about $2.3 \mathrm{mg}$ of betalains per $100 \mathrm{~g}$ of fresh fruit (Hernández-López and others 2008). Betalains have shown potent antiradical-scavenging activity in-vitro (Butera et al., 2002; Cai, Sun, \& Corke, 2003; Pavlov, Kovatcheva, Georgiev, Koleva, \& Ilieva, 2002). Human bioavailability studies showed evidence for oxidative stress prevention through intestinal absorption (Tesoriere, Butera, Pintaudi, Allegra, \& Livrea, 2004). Wu et al. (2006) concluded that the peel of red pitaya, which contains the same betalainic pigments, had high antioxidant activity and showed strong inhibitory in-vitro melanoma cell proliferation. Reynoso-Camacho, Martinez-Samayoa, Ramos-Gomez, Guzmán y Salgado (2015) tested the hypoglycemic and antioxidant effects 
of Myrtillocactus geometrizans berries in streptozotocin-induced diabetic rats, highlighting the importance of berrycactus fruit betalains as adjuvant in the treatment of diabetes and renal complications.

Preserving the beneficial properties of betalain compounds in food during processing can be challenging if high temperatures are applied. However, if the thermal process is neither extensive nor extreme, this degradation is partially reversible (Castellar, Obón, Alacid, \& Fernández-López, 2003). Also, different forms of radioactive light have been shown to degrade these compounds. Under dark conditions, stability is at least double that of normal visible light conditions (Delgado-Vargas, Jiménez, \& Paredes-López, 2000). Finally, using minimal water in the process of extracting betalains has been shown to stabilize these molecules (Gokhale \& Lele, 2014).

Drying is an ancient preservation method which extends product shelf-life by reducing or eliminating microbiological spoilage. Many drying methods cause flaws in the food, such as hardening, woody-texture, low rehydration capacity, loss of cellular integrity, and loss of nutritional quality. Chemical degradation enzymatically or by the Maillard reaction along with many other processes, degrade the quality and potential benefits of foods (Barbosa-Cánovas \& Vega-Mercado, 2000). For that reason, the study of different drying technologies is important to improve the quality of these foods.

Freeze-drying has been shown to be a good alternative to preserve labile and photooxidable compounds in food, as well as creating a less compact product with good rehydration capacities (St. George \& Cenkowski, 2009). Détente Instantanée Contrôlée (DIC, French for Instant Controlled Pressure Drop) is a hydro-thermo-mechanical pre-treatment involving high pressures, followed by an instant pressure drop that changes the texture in the product with a less compact structure that facilitates further extraction, drying, freezing, and other unit operations (Ratti, 2009).

Marginal research has been published on the drying of cactus-fruits, nevertheless showing the impact on the betalainic pigments and antioxidant capacity. This research identifies the changes occurring in berrycacti, while using freeze-drying or Instant Controlled Pressure Drop, advancing the knowledge in the field of dried foods. This research highlights proximal analysis, color parameters, bioactive compounds and in-vitro antioxidant capacities of the berrycacti after the application of the drying treatment.

The novelty of this work highlights berrycacti and its betalainic pigments and antioxidant capacity present even after being processed. On the other hand, this work aims to use a sustainable crop to provide added value to berrycacti.

\section{Materials and Methods}

\subsection{Reagents and Solvents}

Reagents like 2,2-diphenyl-1-picrylhydrazyl (DPPH), 1, 6-hydroxy-2,5,7,8-tetramethylchroman-2-carboxylic acid (Trolox), 2,2'-azino-bis (3-ethylbenzothiazoline-6-sulphonic acid) (ABTS), potassium persulfate, potassium phosphate-buffered saline (PBS), sodium carbonate, acetate buffer, 2,4,6-tris (2-pyridyl)-s-triazine (TPTZ), chlorhydric acid, ferric chloride, Folin Ciocalteu reagent, gallic acid, vanillin, catechin, metaphosphoric acid, acetic acid and indophenol were supplied by Sigma-Aldrich (St. Louis, MO, USA), ACS reagent and $\geq 98 \%$ purity.

Solvents like methanol and ethanol were HPLC grade and supplied by KARAL (Leon, Gto., Mexico).

\subsection{Biological Material}

Berrycactus fruit (M. geometrizans) was the biological material, harvested from the community of Pie de Gallo, located in Querétaro, México ( $\left.20^{\circ} 47^{\prime} 28.8^{\prime \prime} \mathrm{N}, 100^{\circ} 30^{\prime} 09.5^{\prime \prime} \mathrm{W}\right)$ between May and July 2013, at different maturation stages for the determination of an optimal (section 2.3).

Only the ripe berrycacti were washed after harvest, and flower buds were removed. The other berrycacti were discarded. The ripe fruit samples were separated into three batches. Batch 1 was stored at $-40{ }^{\circ} \mathrm{C}$ until physicochemical quantifications and in-vitro antioxidant capacity assays were performed. Batch 2 was separated into individual trays at $-40{ }^{\circ} \mathrm{C}$ in preparation to further freeze-drying treatments. Batch 3 was used immediately for Instant Controlled Pressure Drop drying treatments. All analyses were performed in triplicate to minimize the experimental error as determined by standard deviation calculations.

\subsection{Determination of Optimal Degree of Maturation}

Samples of berrycacti collected in different maturation stages ranging from unripe (green berry), changing (purple with some green hue notes), ripe (purple but firm fruit) to overripe (purple and soft to touch) were compared. 
Weight of berrycacti (g) was recorded using an O'Haus Pioneer scale. Diameter and length were measured using a millimetric Vernier (Westward). Moisture content, using the AOAC (2012) 934.01 method. pH was measured, after mashing some berrycacti, with a Thermo Scientific $\mathrm{pH}$ benchtop potentiometer. Total titratable acidity (TTA) was determined potentiometrically by addition of $\mathrm{NaOH} 0.1 \mathrm{~N}$ until pH 8.6 was achieved, this value was expressed as a percentage of TTA. Total soluble solids (TSS) were determined with an ABBE refractometer (Model 1211, Atago Co., LTD, Japan) expressed in ${ }^{\circ}$ Brix.

Soluble phenol analysis was carried out on an extract prepared by weighting $20 \mathrm{~g}$ of fresh berries and homogenized with $20 \mathrm{~mL}(1 \% \mathrm{HCl})$ acidified methanol, that was centrifuged for 10 minutes at $6000 \mathrm{rpm}$ in a Hermle-Z 383K centrifuge (Equipar, Germany) and kept in absence of light at $4{ }^{\circ} \mathrm{C}$. The phenol content was measured using a modified (Tavares et al., 2010) Folin-Ciocalteu procedure using a microplate and measured at $765 \mathrm{~nm}$. The results were expressed in $\mathrm{mg}$ of gallic acid equivalents per $\mathrm{mL}$ of berrycactus extract.

Antioxidant capacity was determined by the scavenging test (Fukumoto \& Mazza, 2000) with 2,2-diphenyl-1-picrylhydrazyl (DPPH) radical measured at $515 \mathrm{~nm}$ using a visible-UV microplate reader (X Mark Microplate Reader, Bio-Rad Laboratories, Inc., Japan). A calibration curve was prepared with different concentrations of Trolox as standard and results were expressed as micromole Trolox equivalents $/ 100 \mathrm{~g}(\mu \mathrm{mol} \mathrm{T}$ eq/100 g). Total betalain content of berrycactus extracts were spectrophotometrically measured at 538, 700 and $480 \mathrm{~nm}$ (Nilsson, 1970). The betalain content was calculated using the equations (Eq.1 and 2) from Cai y Corke (1999). Then, betacyanins were calculated as equivalents of betanin $(\mathrm{mg} \mathrm{BN} \mathrm{eq} / \mathrm{kg})$, and betaxanthins as equivalents of indicaxanthin (mg IX eq/kg); total betalain content were calculated by the mathematical addition of these two and were expressed in $\mathrm{mg} / \mathrm{kg}$.

$$
\operatorname{Betacyanin}\left(\frac{\mathrm{mg}}{\mathrm{L}}\right)=\frac{\left(\mathrm{A}_{538} \times \mathrm{DF} \times \mathrm{M}_{\mathrm{w}} \times 100\right)}{(\varepsilon \times \mathrm{L})}
$$

Where:

$\mathrm{A}_{538}=$ absorption value at betanin $\lambda \max (538 \mathrm{~nm})$ corrected by the absorption at $700 \mathrm{~nm}$

$\mathrm{DF}=$ dilution factor

$\mathrm{Mw}=$ betanin molecular weight $\left(550 \mathrm{~g} \mathrm{~mol}^{-1}\right)$

$\varepsilon=$ betanin molar extinction coefficient $\left(60,000 \mathrm{~L} \mathrm{~mol}^{-1} \mathrm{~cm}^{-1}\right)$

$\mathrm{L}=$ path length $(1 \mathrm{~cm})$ of the cuvette

$$
\text { Betaxanthin }\left(\frac{\mathrm{mg}}{\mathrm{L}}\right)=\frac{\left(\mathrm{A}_{480} \times \mathrm{DF} \times \mathrm{M}_{\mathrm{W}} \times 100\right)}{(\varepsilon \times \mathrm{L})}
$$

Where:

$\mathrm{A}_{480}=$ absorption value at indicaxanthin $\lambda \max (480 \mathrm{~nm})$ corrected by the absorption at $700 \mathrm{~nm}$

$\mathrm{Mw}=$ indicaxanthin molecular weight $\left(308 \mathrm{~g} \mathrm{~mol}^{-1}\right)$

$\varepsilon=$ indicaxanthin molar extinction coefficient $\left(48,000 \mathrm{~L} \mathrm{~mol}^{-1} \mathrm{~cm}^{-1}\right)$.

$\mathrm{L}=$ path length $(1 \mathrm{~cm})$ of the cuvette

The optimal maturation stage was determined by comparing measured parameters such as TSS, acidity and antioxidant capacity. This stage was used for further drying experimental testing.

\subsection{Drying Techniques}

\subsubsection{Freeze-drying (FD)}

FD was applied to berrycacti previously frozen at $-40^{\circ} \mathrm{C}$ in trays for at least 24 hours. Experiments were carried out in a LabConco FreeZone Triad (Kansas City, USA) where the freeze-dryer plate reached an initial freezing temperature of $-50{ }^{\circ} \mathrm{C}$ followed by sublimation and desorption performed at constant vacuum.

Central composite rotatable design was employed to evaluate the effect of FD operating parameters. The independent variables $(\mathrm{n}=2)$ were the plate's final temperatures (PFT) $\left(26,30,40,50\right.$ and $\left.54{ }^{\circ} \mathrm{C}\right)$ and heating rates (HR) $\left(1.6,2.0,3.0,4.0\right.$ and $\left.4.4^{\circ} \mathrm{C} / \mathrm{h}\right)$.

\subsubsection{Instant Controlled Pressure Drop (DIC)}

Pre-drying of berrycacti was performed inside a cabinet dryer UNB 800 Model (Memmert, Germany), with air at $50{ }^{\circ} \mathrm{C}, 265 \mathrm{~Pa}$ partial pressure of vapor and $1.2 \mathrm{~m} / \mathrm{s}$ of air flux. This pre-drying treatment was carried out until 
initial moisture content was achieved $(10,14,20,26$ or $30 \%$ dry basis (DB)). The pre-dried fruit samples were then placed inside a chamber in the DIC equipment (LABIC0.1, ABCAR-DIC Process, La Rochelle, France). An initial vacuum of $0.003 \mathrm{MPa}$ was established. Saturated steam was injected to the reactor $(0.10,0.17,0.28,0.38$ or $0.45 \mathrm{MPa})$; once the chamber was pressurized, it was maintained for a given time $(5,13,25,37$ or 45 seconds) and instantly decompressed towards vacuum of $0.003 \mathrm{MPa}$. After a vacuum stage period time, pressure was released toward the atmospheric pressure and fruit samples were removed from the reactor. A post-drying stage was performed inside the cabinet dryer at $50{ }^{\circ} \mathrm{C}$ until the berrycactus samples achieved a constant weight, also known as an equilibrium where there is no more loss of moisture.

Central composite rotatable design was employed to evaluate the effect of DIC operating parameters. The independent variables $(n=3)$ were saturated steam pressure $(P)$, processing time $(t)$ and initial moisture content of the sample (M), ranging from 0.1 to $0.45 \mathrm{MPa}, 5$ to 45 seconds, and 10 to $30 \% \mathrm{DB}$, respectively.

\subsection{Proximal Analysis and Color Parameters}

Moisture (934.01), ash (940.26), ether extract (920.85) and nitrogen (960.52) were measured according to the Association of Official Analytical Chemists (AOAC) standards using the AOAC (2012) methods. The total protein was determined using the conversion factor of 6.25 multiplied by the nitrogen measurements. Soluble fiber was determined by the enzymatic-gravimetric method from Prosky, Asp, Schweizer, DeVries y Furda (1988). The remaining percentage represented carbohydrates. All results were expressed as percentage in a dry basis (DB). The color parameters of the dried berry fruits, $\mathrm{L}^{*}, \mathrm{a}^{*}, \mathrm{~b}^{*}$, chroma and hue were determined using a Minolta CM508D colorimeter (Metro Lab International, Japan).

\subsection{Antioxidant Capacity Assays}

For quantifications of antioxidant capacity as well as soluble phenols, condensed tannins, betacyanins and betaxanthins, a methanolic berrycactus extract was prepared from the dried samples as previously mentioned in section 2.3.

For all the dried samples, in-vitro antioxidant capacity was determined by three methods. The first determination was performed using DPPH radical as described in section 2.3. The second method, used ABTS radical as described by Re et al. (1999). The last antioxidant capacity method was the ferric reducing antioxidant power (FRAP) as described by Benzie y Strain (1996).

\subsection{Bioactive Compounds Quantification}

Non-extractable polyphenols (NEPP) were determined according to Saura-Calixto (1998) as a treatment of the residue from the initial extraction with acidified methanol with butanol/ $\mathrm{HCl}(97.5: 2.5, \mathrm{v} / \mathrm{v})$ at $100{ }^{\circ} \mathrm{C}$ for $60 \mathrm{~min}$ in the presence of $\mathrm{FeCl}_{3}$, followed by spectrophotometry measurement at $555 \mathrm{~nm}$ using a Genesis $2100 \mathrm{UV} / \mathrm{Vis}$ spectrophotometer (Model G105, Thermo Fischer Scientific, China) using catechin as standard. Results were expressed in $\mathrm{mg}$ catechin equivalents $/ \mathrm{kg}(\mathrm{mg} \mathrm{CT} \mathrm{eq} / \mathrm{kg})$.

For soluble phenols quantification, an aliquot of the initial methanolic extract was used with the Folin Ciocalteu reagent (Singleton, Orthofer, \& Lamuela-Raventos, 1999) and measured at $760 \mathrm{~nm}$ using the UV/Vis spectrophotometer after comparing the readings with a standard curve of gallic acid. Results were expressed in $\mathrm{mg}$ of gallic acid equivalents/ $\mathrm{kg}$ of sample ( $\mathrm{mg} \mathrm{GA} \mathrm{eq} / \mathrm{kg}$ ).

To quantify the condensed tannins, an aliquot of the supernatant from the initial methanolic extract was treated with vanillin/methanol (1\%) and samples were measured at $500 \mathrm{~nm}$ according to the vanillin method (Deshpande, Cheryan, Salunkhe, \& Luh, 1986); results were reported as $\mathrm{mg}$ catechin equivalents $/ \mathrm{kg}(\mathrm{mg} \mathrm{CT} \mathrm{eq} / \mathrm{kg}$ ) after comparing readings with a catechin standard curve.

The determination of betacyanins and betaxanthins in the initial extract was performed as previously described in section 2.3; while ascorbic acid (967.21) was determined following the AOAC (2012) methods.

\subsection{Water Holding Capacity and Texture Analysis for Dried Products}

Water holding capacity (WHC) was evaluated on powdered FD and DIC dried berrycacti. On a 30-mL centrifuge plastic tube, $22.5 \mathrm{~mL}$ of water were added to $2.5 \mathrm{~g}$ of berrycactus powder at room temperature. Sample tubes were hand shaken vigorously for 1 minute and then incubated for 1 hour at room temperature. Then, they were centrifuged at $3500 \mathrm{rpm}$ for 30 minutes in a Hermle-Z 383K centrifuge with partial intervals every 5 minutes to remove the supernatant resulted throughout the centrifugation process. The final moisture content was calculated as the cake weight loss and expressed as percentage of water holding capacity (DB) (Larrauri, Rupérez, Borroto, \& Saura-Calixto, 1996).

Texture properties of dried berrycactus samples were evaluated in a MTS-QTEST11 (Universal Testing Machine, 
Eden Prairie, MN, USA) using the Kramer shear cell $(53 \mathrm{~mm}$ x $56 \mathrm{~cm})$ with ten shear cutting blades, alternating $(65 \mathrm{~mm})$ which are loosely suspended from a blade holder. The compression ratio used was $50 \%$ deformation from the initial height at a rate of $200 \mathrm{~mm} / \mathrm{min}$. Results were obtained from the Tension Zero ver. 1.0 software (Hernández \& Sariñana, 2007) showing the tenderness of the dried berry reported as the peak force $(\mathrm{N})$.

\subsection{Statistical Analysis}

Statistical analysis was performed using the Statistica software v 13 (Dell, Inc., Tulsa, OK, USA). For each drying method data sets, analysis of variance (ANOVA) was applied to evaluate any significant differences ( $\mathrm{p}<$ 0.05). The Fisher Least Square Difference (LSD) test was conducted for all the significant factors. A new data set was constructed by dividing the final value of each evaluated parameter with its initial value getting a Delta of this change. Then, ANOVA and LSD were applied to evaluate significant differences $(p<0.05)$ between drying methods for each individual parameter.

General Discriminant Analysis (GDA) was applied to the data to discriminate between the maturation stages and secondly between the dehydration processes. The forward stepwise method ( $\mathrm{p}$ inclusion $0.05, \mathrm{p}$ exclusion 0.05 ) was performed to minimize the model sizes.

\section{Results and Discussions}

\subsection{Determination of Optimal Degree of Maturation}

Samples of berrycacti with four different maturation stages showed significant changes in moisture content, Total Titratable Acidity (TTA), Total Soluble Solids (TSS), soluble phenols, antioxidant capacity (DPPH) and total betalains (Table 1). Moisture content and TTA reduced significantly, $10.38 \%$ and $30.95 \%$ respectively, as the berrycactus matures; on the other hand, TSS (19.08\%), soluble phenols $(85.92 \%)$ and total betalains $(44.43 \%)$ increased significantly, comparing the overripe to the unripe berrycacti. Antioxidant capacity in the berrycacti demonstrated an increase between the unripe and ripe stages (32.61\%). However, the values slightly decreased while achieving the overripe stage (26.27\%) compared to the unripe.

Table 1. Physicochemical properties of berrycactus

\begin{tabular}{|c|c|c|c|c|c|}
\hline & P-value & Unripe & Changing & Ripe & Overripe \\
\hline Weight $(\mathrm{g})$ & 0.446 & $0.707^{\mathrm{a}}$ & $0.643^{\mathrm{a}}$ & $0.557^{\mathrm{a}}$ & $0.590^{\mathrm{a}}$ \\
\hline Diameter $(\mathrm{cm})$ & 0.596 & $1.000^{\mathrm{a}}$ & $0.967^{\mathrm{a}}$ & $0.867^{\mathrm{a}}$ & $0.900^{\mathrm{a}}$ \\
\hline Length $(\mathrm{cm})$ & 0.596 & $1.300^{\mathrm{a}}$ & $1.233^{\mathrm{a}}$ & $1.200^{\mathrm{a}}$ & $1.333^{\mathrm{a}}$ \\
\hline Moisture content (\% DB) & $0.003 * *$ & $0.780^{\mathrm{b}}$ & $0.760^{\mathrm{b}}$ & $0.712^{\mathrm{a}}$ & $0.699^{\mathrm{a}}$ \\
\hline $\mathrm{pH}$ & 0.233 & $4.75^{\mathrm{a}}$ & $4.89^{\mathrm{a}}$ & $4.70^{\mathrm{a}}$ & $4.71^{\mathrm{a}}$ \\
\hline Total titratable acidity (\%) & $0.002 * *$ & $12.18^{\mathrm{c}}$ & $9.88^{\mathrm{b}}$ & $9.73^{\mathrm{ab}}$ & $8.41^{\mathrm{a}}$ \\
\hline Total soluble solids ( ${ }^{\circ} \mathrm{Brix}$ ) & $0.000 * *$ & $29.67^{\mathrm{a}}$ & $31.33^{\mathrm{b}}$ & $33.33^{\mathrm{c}}$ & $35.33^{\mathrm{d}}$ \\
\hline Soluble phenols $(\mathrm{mg} \text { GA eq/ } \mathrm{mL})^{1}$ & $0.000 * *$ & $6.89^{\mathrm{a}}$ & $9.63^{\mathrm{b}}$ & $11.74^{\mathrm{c}}$ & $12.81^{\mathrm{d}}$ \\
\hline 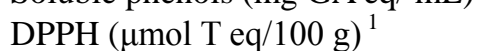 & $0.000 * *$ & $7215.3^{\mathrm{b}}$ & $8334.0^{\mathrm{c}}$ & $9568.5^{\mathrm{a}}$ & $9110.6^{\mathrm{a}}$ \\
\hline Total betalains $(\mathrm{mg} / \mathrm{kg})$ & $0.000 * *$ & $64575^{\mathrm{a}}$ & $73062^{\mathrm{b}}$ & $84519^{c}$ & $93264^{\mathrm{d}}$ \\
\hline
\end{tabular}

${ }^{1} \mu \mathrm{mol} \mathrm{T}$ eq/100 g: $\mu \mathrm{mol}$ of Trolox equivalents/100 g of DB. mg GA eq $/ \mathrm{kg}: \mathrm{mg}$ of gallic acid equivalents $/ \mathrm{kg}$ of DB.

"Significance at $p \leq 0.01$ is marked with two asterisks

Means without a common letter through rows are significantly different $(\mathrm{p} \leq 0.05)$

Coria Cayupán, Ochoa y Nazareno (2011) found very variable TSS in the pulp of Opuntia megacantha, Opuntia ficus-indica and Opuntia spp. during the fruit development. However, particularly O. megacantha betalain concentration, soluble phenols, antioxidant capacity (DPPH and ABTS) increased in the pulp and peel while ripening, similar to the results of this study. Coria Cayupán et al. (2011) also conclude that antioxidant capacity increases could be attributed to the increase in ascorbic acid and other active compounds as polyphenols and betalains.

Herrera-Hernández et al. (2011) prepared fractions for total phenols, betacyanins and betaxanthins and observed a decrease in berrycactus total phenols $(81.5 \%)$ in ripe fruit compared to the unripe fruit contrary to what was observed in this research. Betacyanins in ripe (44.9\%) and overripe (92.0\%) fruits increased compared to the unripe berrycacti, opposite, betaxanthins diminished as the fruit ripened. The same authors also reported the antioxidant activity in their three fractions as Trolox Equivalent Antioxidant capacity, obtaining a decrease in the ripe and overripe berrycacti, compared to the unripe for total phenols (45.3\% and $72.9 \%$, respectively) and betacyanin fractions $(57.4 \%$ and $66.5 \%$, respectively); meanwhile, for the betaxanthin fraction, the values 
obtained were less affected compared to the unripe fruit.

General Discriminant Analysis (GDA) was performed to separate samples per the maturation stages. Forward stepwise analysis led to the selection of two parameters: total betalains and antioxidant capacity (DPPH). With the selected parameters, $100 \%$ of the samples were correctly classified according to the maturation stage (Fig. 1). This confirms the selection, the ripe berrycactus stage, to optimize the highest antioxidant capacity and betalain content for further dehydration.

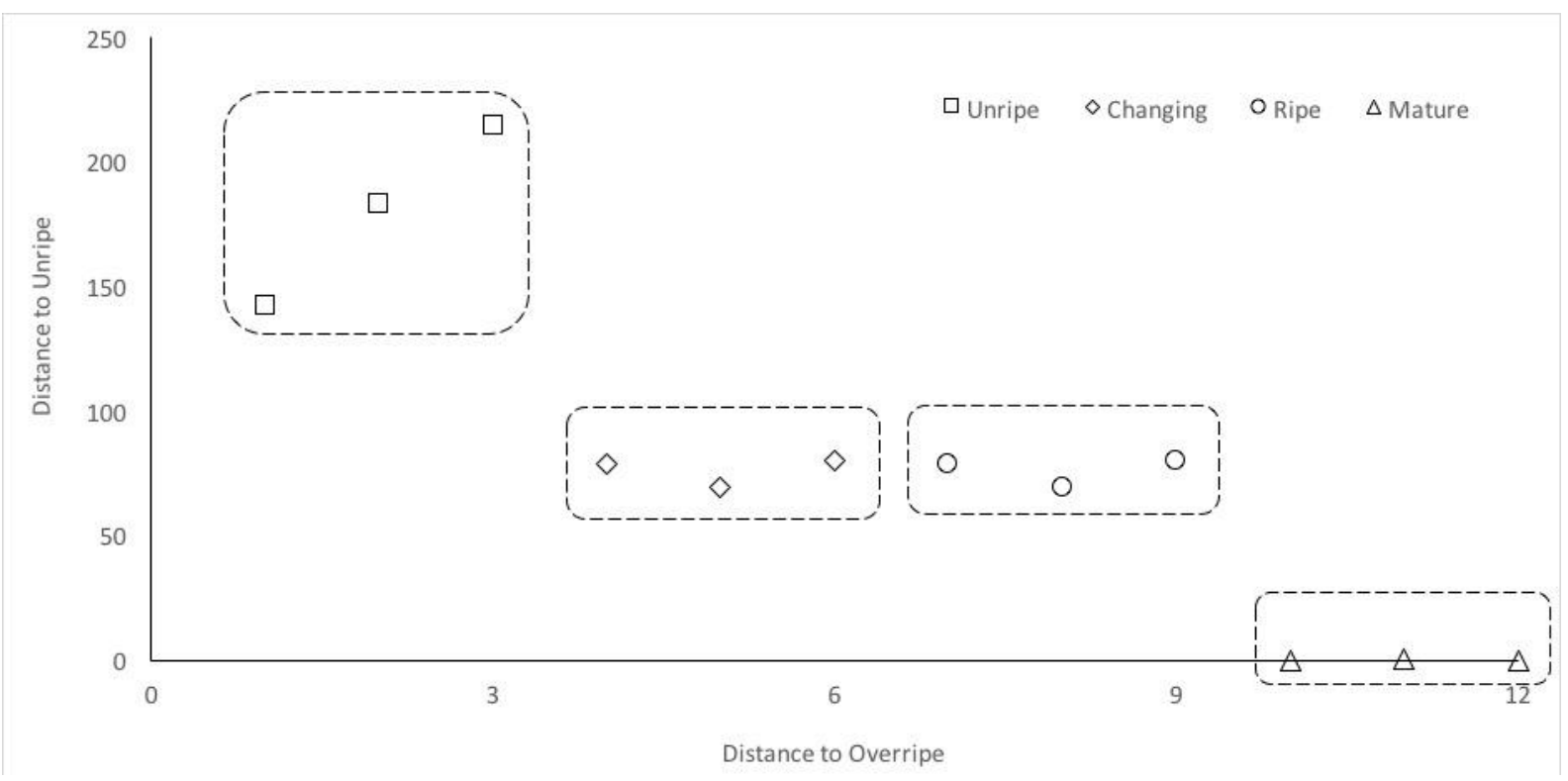

Figure 1. Cooman's graph for maturation stages observed in berrycactus

The graph illustrates the Mahalanobis distances between the maturation stages in berrycacti, showing all four stages were clearly different among each other and samples can be correctly classified as unripe, changing, ripe and overripe berrycacti.

\subsection{Freeze-drying ANOVA}

ANOVA did not show significant differences ( $\mathrm{p}>0.05)$ for any proximal analysis parameters.

However, when analyzing the color changes, there was a significant difference for the $\mathrm{a}^{*}$ parameter $(\mathrm{p}=0.040)$ which describes the redness of the fruit while changing the HR for the FD treatment. For the antioxidant assays, ABTS showed significant differences $(p=0.015)$ for the interaction between the PFT and the HR while for FRAP significant differences $(\mathrm{p}=0.004)$ were observed when changing the HR. Furthermore, quantification of bioactive compounds such as soluble phenols, NEPP, condensed tannins, betacyanins, betaxanthins and ascorbic acid showed no significant differences neither for WHC nor for tenderness (data not shown). Fig. 2 shows three graphs on the fitted surface response for the significant parameters during the FD treatments over the tested conditions; color parameter a* (Fig. 2.a), antioxidant capacity measured with ABTS (Fig. 2.b) and FRAP (Fig. 2.c). The research concludes that the optimal conditions for a FD treatment was plate's final temperature of 26 ${ }^{\circ} \mathrm{C}$ with a constant heating rate of $3^{\circ} \mathrm{C} / \mathrm{h}$. 
a)

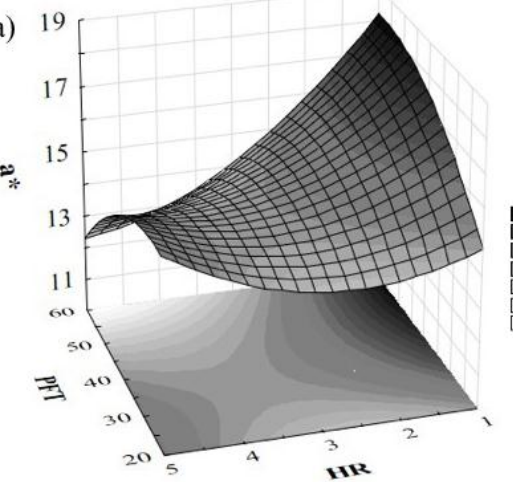

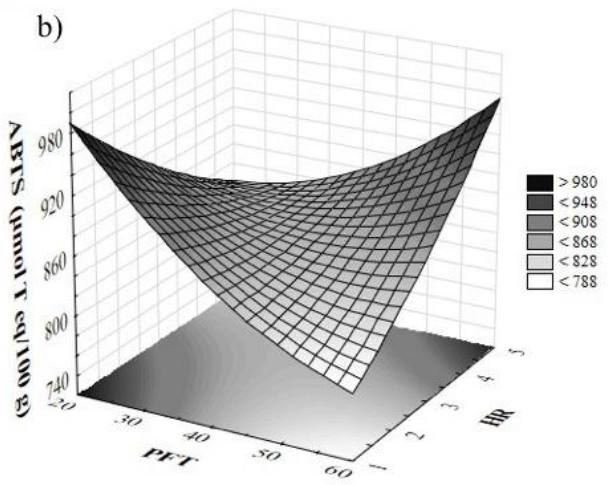

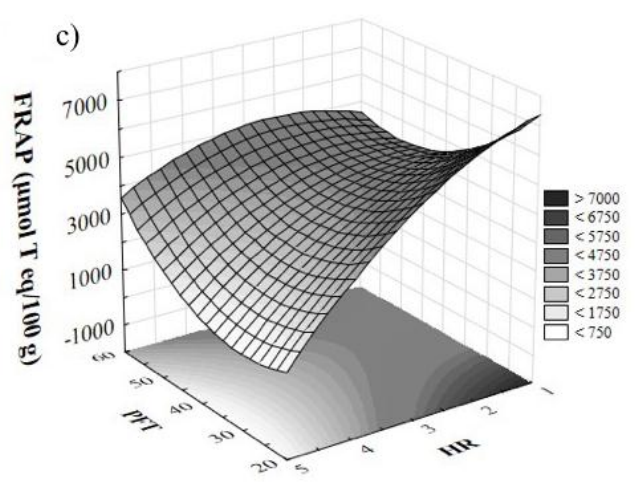

Figure 2. Fitted surface response for significant parameters during FD treatments

a) Color parameter a*. b) ABTS antioxidant capacity. c) FRAP antioxidant capacity.

a) The surface response for the color parameter a* (redness) shows that higher the PFT, the loss of redness is also higher in the berrycacti.

b) The surface response for ABTS antioxidant capacity shows that higher PFT, higher the loss of in-vitro antioxidant capacity in the berrycactus.

c) FRAP antioxidant capacity surface response graphs shows that higher HR, higher the in-vitro antioxidant capacity in the berrycactus.

Viloria-Matos, Corbelli-Moreno, Moreno-Álvarez y Belén (2002) evaluated the betalain stability in prickly pear (Opuntia boldinghii) pulp after freeze-drying under conditions of 12 hours of processing, $70 \mathrm{mmHg}$ of pressure, $-20{ }^{\circ} \mathrm{C}$ of chamber's temperature and $20^{\circ} \mathrm{C}$ of plate's constant temperature. They reported good stability for betalain pigment with this method resulting in a good shelf life. Liaotrakoon, De Clercq, Lewille y Dewettinck (2012) observed in red-flesh dragon fruit (Hylocereus polyrhizus), a good retention of vitamin C and a slight increase in $\mathrm{L}^{*}$ and $\mathrm{a}^{*}$ and decrease in $\mathrm{b}^{*}$.

\subsection{DIC ANOVA}

ANOVA showed significant differences $(\mathrm{p}<0.05)$ only for the interactions between the factors tested. Individual factors did not show significant differences for any evaluated parameter (Fig. 3). 

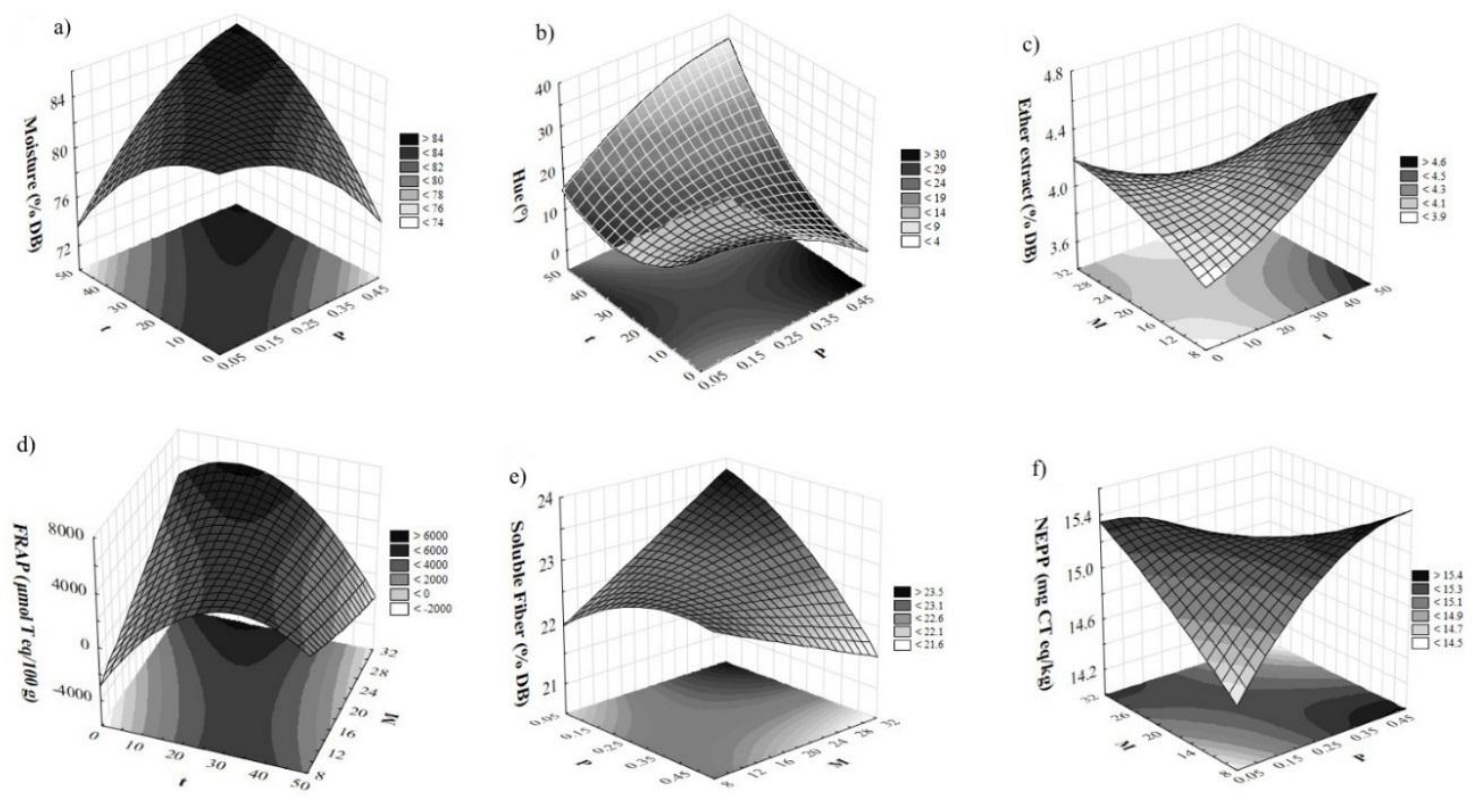

Figure 3. Fitted surface response for significant parameters during the DIC treatments

a) Moisture (\% DB). b) Color hue. c) Ether extract (\% DB). d) FRAP antioxidant capacity ( $\mu$ mol T eq $/ 100$ g). e) Soluble fiber ( $\%$ DB). f) $\operatorname{NEPP}(\mathrm{mg}$ CT eq $/ \mathrm{kg})$.

a) The surface response for the residual moisture content $(\% \mathrm{DB})$ shows that higher $\mathrm{t}$, there is less moisture present in the berrycacti after dehydration.

b) Color hue surface response shows that higher $t$, there is less hue in the berrycacti after dehydration.

c) Surface response for ether extract shows that higher $t$, there is better extraction of the fat content in the berrycacti.

d) The surface response for FRAP antioxidant capacity shows that higher M (initial moisture of the berrycacti), lower the loss of FRAP in-vitro antioxidant capacity in the berrycactus.

e) Surface response graphs for shows that higher M, lower content of soluble fiber available in the berrycacti.

f) Surface response graphs for shows that higher M, lower content of NEPP available in the berrycacti.

The interaction between $\mathrm{P}$ and $\mathrm{t}$ was significant for the final moisture content ( $\mathrm{p}=0.047$; Fig. 3.a) and the color hue ( $\mathrm{p}=0.024$; Fig. 3.b), this are meaningful results due to a better extraction of moisture after the process as well as a better shade obtained in the berrycactus color. The interaction between $t$ and $\mathrm{M}$ was significant for the ether extract ( $\mathrm{p}=0.042$; Fig. 3.c) and the antioxidant capacity reported with FRAP ( $\mathrm{p}=0.030$; Fig. 3.d), meaning again, a better extraction of the fat content in the berrycacti and higher antioxidant capacity with this in-vitro analysis. Finally, the interaction between $\mathrm{P}$ and $\mathrm{M}$ was significant for the fiber content ( $\mathrm{p}=0.006$; Fig. 3.e) and NEPP ( $p=0.005$; Fig. 3.f) suggesting better availability of these compounds in the fruit.

This comparative analysis shows neither WHC nor tenderness were significantly different between the FD and DIC methods. DIC has been tested in different fruits (Alonzo-Macías, Cardador-Martínez, Mounir, Montejano-Gaitán, \& Allaf, 2013; Haddad, Mounir, Sobolik, \& Allaf, 2008; Mounir, Allaf, Berka, Hassani, \& Allaf, 2014) where authors report shorter drying and rehydration times, as well as lower final water content in the fruits due to the rapid removal of water as the diffusivity was improved. Alonzo-Macías et al. (2013) reported an increase of antioxidant activity in strawberries with DIC compared to hot air drying and freeze-drying. Research articles have not indicated any significant changes in the soluble fiber, non- extractable polyphenols, such as proanthocyanidins or color changes for fruits using the DIC technology.

Based upon the parameters showing the fitted surface response (Fig. 3 A-F), and particularly highlighting the antioxidant capacity (FRAP), NEPP and the color hue of the berry after the DIC process, concluding that the optimal conditions are $\mathrm{P}$ of $0.45 \mathrm{MPa}, \mathrm{t}$ of $25 \mathrm{~s}$ and an M of $20 \% \mathrm{DB}$. 


\subsection{Variation of Berrycactus Parameters after Dehydration}

Overall effect of FD and DIC treatments were compared against fresh fruits over the parameters shown in Table 2. The two drying methods used throughout the process demonstrated higher antioxidant activities than the fresh fruit, regardless of the methodologies used for its in-vitro determination, highlighting the increase in FRAP determination for FD (33.6\%) and for DIC (41.5\%). Furthermore, for condensed tannins, such increase was 9.0\% and $13.5 \%$ for FD and DIC, respectively. Retention of betalains after FD was $95.1 \%$ and DIC was $87.1 \%$ due to the higher retention of betacyanins, which are the most abundant pigment in berrycacti. The retention of ascorbic acid was greater than $98 \%$ for both methods despite of the thermal exposure in the DIC treatment.

Table 2. Comparison of fresh and dried FD and DIC berrycacti

\begin{tabular}{|c|c|c|c|c|}
\hline & Fresh & $p$-value & $\Delta$ for $\mathrm{FD}^{1}$ & $\Delta$ for DIC $^{1}$ \\
\hline Moisture (\% DB) & $80.29 \pm 2.63$ & $0.022 *$ & $0.986^{\mathrm{a}}$ & $1.029^{\mathrm{b}}$ \\
\hline Ash (\% DB) & $3.69 \pm 0.33$ & 0.816 & $1.009^{\mathrm{a}}$ & $1.000^{\mathrm{a}}$ \\
\hline Ether extract (\% DB) & $4.06 \pm 0.19$ & 0.719 & $1.000^{\mathrm{a}}$ & $1.000^{\mathrm{a}}$ \\
\hline Protein $(\% \mathrm{DB})$ & $4.99 \pm 0.28$ & 0.583 & $0.990^{\mathrm{a}}$ & $0.989^{\mathrm{a}}$ \\
\hline Soluble fiber (\% DB) & $22.52 \pm 0.39$ & $0.010 * *$ & $1.004^{\mathrm{a}}$ & $1.018^{\mathrm{b}}$ \\
\hline Carbohydrates (\% DB) & $64.83 \pm 0.29$ & 0.185 & $1.002^{\mathrm{a}}$ & $0.997^{\mathrm{a}}$ \\
\hline $\mathrm{L}^{*}$ & $32.98 \pm 6.80$ & 0.483 & $1.034^{\mathrm{a}}$ & $1.055^{\mathrm{a}}$ \\
\hline$a^{*}$ & $14.66 \pm 0.62$ & $0.000 * *$ & $0.906^{\mathrm{a}}$ & $1.171^{\mathrm{b}}$ \\
\hline$b^{*}$ & $4.12 \pm 1.25$ & $0.033^{*}$ & $1.488^{\mathrm{a}}$ & $1.239^{\mathrm{b}}$ \\
\hline Chroma & $16.60 \pm 0.46$ & 0.627 & $0.994^{\mathrm{a}}$ & $0.955^{\mathrm{a}}$ \\
\hline Hue $\left({ }^{0}\right)$ & $10.84 \pm 1.93$ & 0.667 & $1.430^{\mathrm{a}}$ & $1.474^{\mathrm{a}}$ \\
\hline DPPH $(\mu \mathrm{mol} T \text { eq/100 g })^{1}$ & $8572.7 \pm 1034.9$ & 0.597 & $1.011^{\mathrm{a}}$ & $1.025^{\mathrm{a}}$ \\
\hline ABTS $\left(\mu \mathrm{mol} T\right.$ eq/100 g) ${ }^{1}$ & $830.3 \pm 24.5$ & $0.009 * *$ & $1.037^{\mathrm{a}}$ & $1.007^{\mathrm{b}}$ \\
\hline $\operatorname{FRAP}(\mu \mathrm{mol} T \text { eq/100 g })^{1}$ & $2901.3 \pm 1202.7$ & 0.913 & $1.336^{\mathrm{a}}$ & $1.415^{\mathrm{a}}$ \\
\hline Soluble phenols (mg GA eq/kg) ${ }^{1}$ & $10070 \pm 500$ & 0.059 & $1.000^{\mathrm{a}}$ & $0.974^{\mathrm{a}}$ \\
\hline Non-Extractable Polyphenols (mg CT eq/kg) ${ }^{1}$ & $14.94 \pm 0.21$ & $0.010 * *$ & $1.004^{\mathrm{a}}$ & $1.018^{\mathrm{b}}$ \\
\hline Condensed tannins (mg CT eq/kg) & $2.20 \pm 0.66$ & 0.733 & $1.090^{\mathrm{a}}$ & $1.135^{\mathrm{a}}$ \\
\hline Betacyanins (mg BN eq $/ \mathrm{kg}){ }^{1}$ & $81.77 \pm 12.75$ & 0.072 & $0.951^{\mathrm{a}}$ & $0.871^{\mathrm{a}}$ \\
\hline Betaxanthins (mg IX eq/kg) ${ }^{1}$ & $0.188 \pm 0.086$ & $0.027 *$ & $0.814^{\mathrm{a}}$ & $0.560^{\mathrm{b}}$ \\
\hline Total betalains $(\mathrm{mg} / \mathrm{kg})$ & $81.96 \pm 12.77$ & 0.071 & $0.951^{\mathrm{a}}$ & $0.871^{\mathrm{a}}$ \\
\hline Ascorbic acid (mg AA eq/kg) ${ }^{1}$ & $248.09 \pm 13.82$ & 0.804 & $0.982^{\mathrm{a}}$ & $0.981^{\mathrm{a}}$ \\
\hline
\end{tabular}

${ }^{1}$ FD: Freeze-drying. DIC: Instant Controlled Pressure Drop. $\mu \mathrm{mol} \mathrm{T}$ eq $/ 100 \mathrm{~g}: \mu \mathrm{mol}$ of Trolox equivalents/100 g of DB. mg GA eq $/ \mathrm{kg}$ : mg of gallic acid equivalents $/ \mathrm{kg}$ of DB. $\mathrm{mg}$ CT eq $/ \mathrm{kg}$ : $\mathrm{mg}$ of catechin equivalents $/ \mathrm{kg}$ of DB. $\mathrm{mg} \mathrm{BN} \mathrm{eq/kg:} \mathrm{mg}$ of betanin equivalents $/ \mathrm{kg}$ of DB. mg IX eq $/ \mathrm{kg}$ : $\mathrm{mg}$ of indicaxanthin equivalents $/ \mathrm{kg}$ of DB. mg AA eq $/ \mathrm{kg}$ : $\mathrm{mg}$ of ascorbic acid equivalents $/ \mathrm{kg}$ of DB.

"Significance at $p \leq 0.05$ is marked with an asterisk; $p \leq 0.01$ is marked with two asterisks.

Means without a common letter are significantly different $(p \leq 0.05)$

ANOVA and LSD tests were applied to the delta value for each evaluated parameter. Final moisture content, soluble fiber, color parameter $\mathrm{a}^{*}$, and NEPP showed significant differences between FD and DIC, where FD showed lower delta values. On the other hand, the delta values for color parameter $b^{*}$, ABTS antioxidant capacity and betaxanthins were significantly lower for DIC treatments. The remaining evaluated deltas were not significant between the two drying methods.

The color parameter $\mathrm{a}^{*}$ exemplifies the color changes observed after the treatments, where FD shows a loss in "redness" compared to DIC where products retain and boost their red color. The $\mathrm{b}^{*}$ parameter, describing the yellowness, increased for both methods compared to the fresh berries. FD showed higher yellowness than DIC due to a possible correlation with the betaxanthin retention.

NEPP are phenolic compounds that are bond to the soluble fiber (Pérez-Jiménez \& Torres, 2011). While comparing the drying treatments, identical increments were noted for NEPP and soluble fiber, validating the correlation establish by the previously mentioned authors. In both cases for FD and DIC, there was an increase of the NEPP compared to the fresh berrycacti. However, this variation was higher for those berrycacti treated with DIC suggesting that DIC increases the availability of these compounds because of the expansion of the cell structure.

Betaxanthins were another bioactive compound which showed a significant difference between the two drying 
methods. Although this parameter decreased after the treatment, the retention was better with FD.

The statistical analysis concluded that there were no significant differences between FD and DIC dehydration. General Discriminant Analysis (GDA) was performed to separate samples according to the drying method. Forward stepwise analysis led to the selection of two parameters: $a^{*}$ and $b^{*}$. With the selected parameters, $95.8 \%$ of the total samples were correctly classified per the drying method (Fig. 4). Only one of the DIC samples was misplaced with the FD samples. Overall they can be perfectly classified into two separated groups. Only color parameters could discriminate between FD and DIC samples. In conclusion, both methods are suitable for preservation of the fruit and its bioactive compounds as well as the antioxidant capacity of the berrycacti.

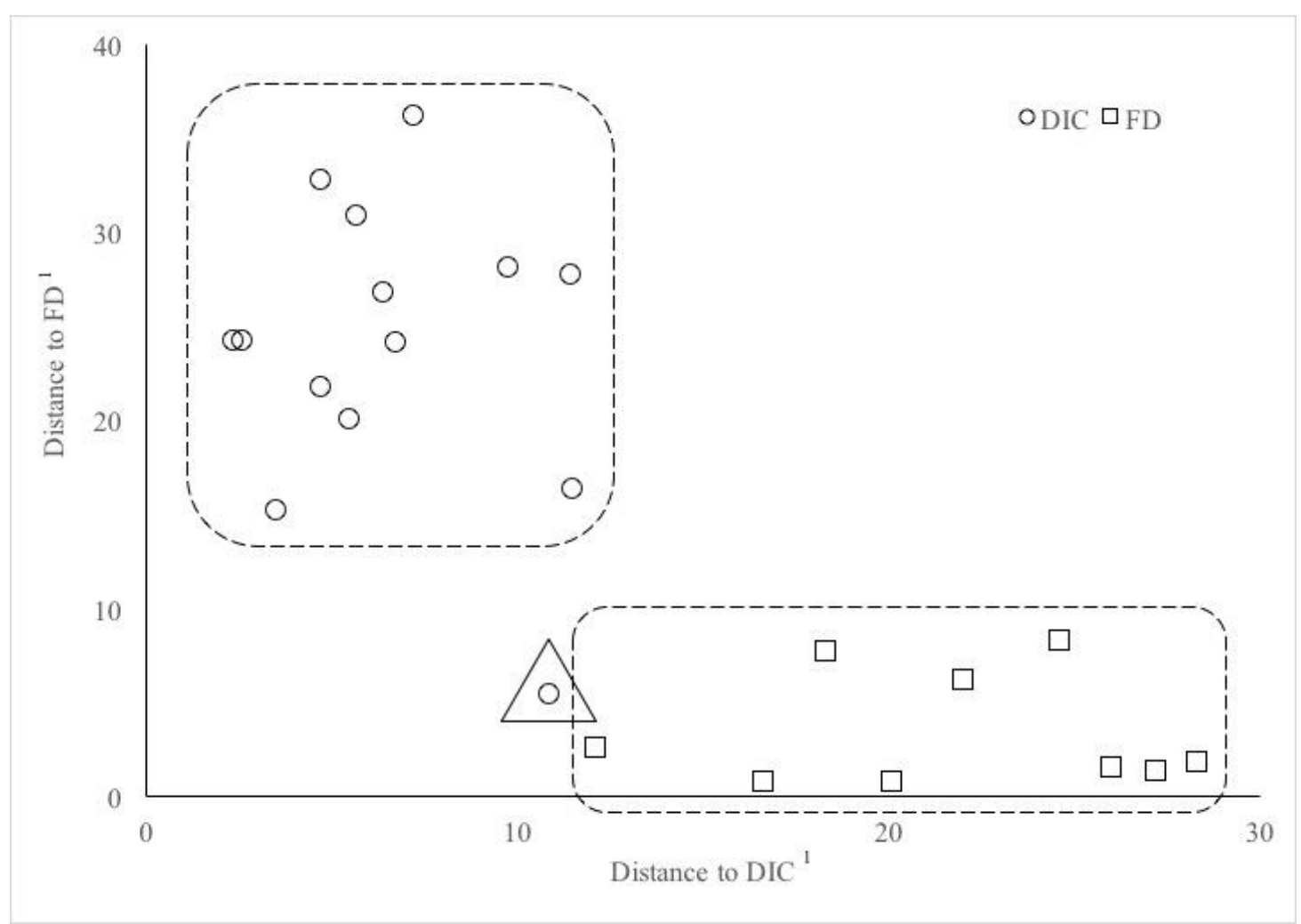

Figure 4. Cooman's graph for dehydration techniques applied to berrycactus

${ }^{1}$ FD: Freeze-drying. DIC: Instant Controlled Pressure Drop.

The graph illustrates the Mahalanobis distances between FD and DIC, showing that the dehydration techniques applied to berrycacti can be differentiated among them and samples could potentially $(95.8 \%)$ be classified correctly according to the drying method applied.

\section{Conclusions}

Based on the DPPH antioxidant capacity and betalain content, the ripe maturation stage was determined as the optimal stage for performing the comparative drying methods on berrycacti.

The comparative analysis of the two drying methods showed only minimal differences in the proximal analysis, color parameters and bioactive compounds content of the berrycacti. Both drying methods demonstrated high antioxidant activities regardless of the methodologies used for its in-vitro determination. Overall, FD and DIC were efficient drying methods for the berrycacti due to good quality attributes of the final products. Moreover, the preservation of the antioxidant properties and the retention of bioactive compounds such as soluble phenols, NEPP, tannins, betacyanins, betaxanthins and ascorbic acid was achieved. These compounds were present after drying treatments possibly aiding as beneficial health promoters in the prevention of chronic diseases such as hypoglycemia. Areas for future research may include the evaluation of individual bioactive compounds in berrycacti during the drying process as well as clinical trials using the dried berrycacti impact on human health.

\section{Acknowledgments}

Mrs. Priscila Santiago-Mora is grateful for the financial support of Consejo Nacional de Ciencia y Tecnología (CONACYT) through doctoral scholarship 269441. 
The authors thank Dr. Klaus Tenbergen, Dr. Joseph M. Ryan and Michelle Teschky for the review of this manuscript.

\section{References}

Alonzo-Macías, M., Cardador-Martínez, A., Mounir, S., Montejano-Gaitán, G., \& Allaf, K. (2013). Comparative Study of the Effects of Drying Methods on Antioxidant Activity of Dried Strawberry (Fragaria var. Camarosa). Journal of Food Research, 2(2), 92. https://doi.org/10.5539/jfr.v2n2p92

AOAC. (2012). Official Methods of Analysis (G. W. Latimer Ed. 19th edition ed.). Washington, D.C.: Association of Official Analytical Chemists

Arias, S. (2010). Diversidad de cactáceas y su aprovechamiento en México. México, D.F.: Instituto de Biología, Jardín Botánico UNAM.

Barbosa-Cánovas, G. V., \& Vega-Mercado, H. (2000). Deshidratación de Alimentos (A. Ibarz Ribas, Trans. E. Acribia Ed.). Zaragoza, España: Aspen Publishers.

Benzie, I. F., \& Strain, J. (1996). The Ferric Reducing Ability of Plasma (FRAP) as a Measure of "Antioxidant Power": The FRAP Assay. Analytical Biochemistry, 239(1), 70-76. https://doi.org/10.1006/abio.1996.0292

Butera, D., Tesoriere, L., Di Gaudio, F., Bongiorno, A., Allegra, M., Pintaudi, A. M., Kohen, R., \& Livrea, M. A. (2002). Antioxidant Activities of Sicilian Prickly Pear (Opuntia ficus indica) Fruit Extracts and Reducing Properties of its Betalains: Betanin and Indicaxanthin. Journal of Agricultural and Food Chemistry, 50(23), 6895-6901. https://doi.org/10.1021/jf025696p

Cai, Y., \& Corke, H. (1999). Amaranthus Betacyanin Pigments Applied in Model Food Systems. Journal of Food Science, 64(5), 869-873. https://doi.org/10.1111/j.1365-2621.1999.tb15930.x

Cai, Y., Sun, M., \& Corke, H. (2003). Antioxidant Activity of Betalains from Plants of the Amaranthaceae. Journal of Agricultural and Food Chemistry, 51(8), 2288-2294. https://doi.org/10.1021/jf030045u

Castellar, R., Obón, J. M., Alacid, M., \& Fernández-López, J. A. (2003). Color Properties and Stability of Betacyanins from Opuntia Fruits. Journal of Agricultural and Food Chemistry, 51(9), 2772-2776. https://doi.org/10.1021/jf021045h

Coria Cayupán, Y. S., Ochoa, M. J., \& Nazareno, M. A. (2011). Health-promoting substances and antioxidant properties of Opuntia sp. fruits. Changes in bioactive-compound contents during ripening process. Food Chemistry, 126(2), 514-519. https://doi.org/10.1016/j.foodchem.2010.11.033

Delgado-Vargas, F., Jiménez, A., \& Paredes-López, O. (2000). Natural Pigments: Carotenoids, Anthocyanins, and Betalains - Characteristics, Biosynthesis, Processing, and Stability. Critical Reviews in Food Science and Nutrition, 40(3), 173-289. https://doi.org/10.1080/10408690091189257

Deshpande, S. S., Cheryan, M., Salunkhe, D., \& Luh, B. S. (1986). Tannin analysis of food products. Critical Reviews in Food Science and Nutrition, 24(4), 401-449. https://doi.org/10.1080/10408398609527441

Fukumoto, L., \& Mazza, G. (2000). Assessing Antioxidant and Prooxidant Activities of Phenolic Compounds. Journal of Agricultural and Food Chemistry, 48(8), 3597-3604. https://doi.org/10.1021/jf000220w

Gokhale, S., \& Lele, S. (2014). Betalain Content and Antioxidant Activity of Beta vulgaris: Effect of Hot Air Convective Drying and Storage. Journal of Food Processing and Preservation, 38(1), 585-590. https://doi.org/10.1111/jfpp.12006

Guzmán-Maldonado, S. H., Villordo, E., González-Chavira, M., Pons-Hernández, J. L., \& Hernández-López, D. (2012). Estudio preliminar de la diversidad genética del género Myrtillocactus en el Estado de Guanajuato La Biodiversidad en Guanajuato: Estudio de Estado (Vol. II, pp. 524). México: Comisión Nacional para el Conocimiento y Uso de la Biodiversidad/ Instituto de Ecología del Estado de Guanajuato.

Haddad, M. A., Mounir, S., Sobolik, V., \& Allaf, K. (2008). Fruits \& Vegetables Drying Combining Hot Air, DIC Technology and Microwaves. International Journal of Food Engineering, 4(6). https://doi.org/10.2202/1556-3758.1491

Hernández-López, D., Vaillant, F., Reynoso-Camacho, R., \& Guzman-Maldonado, S.-H. (2008). Myrtillocactus (cactaceae): botanical, agronomic, physicochemical and chemical characteristics of fruits. Fruits, 63(05), 269-276. https://doi.org/10.1051/fruits:2008042

Hernández, M., \& Sariñana, A. (2007). Diseño Integral de Máquina General de Ensayos de Materiales. . Paper presented at the $5^{0}$ Congreso Internacional Sobre Investigación y Desarrollo Tecnológico (CIINDET), 
Cuernavaca, Morelos, Mexico.

Herrera-Hernández, M. G., Guevara-Lara, F., Reynoso-Camacho, R., \& Guzmán-Maldonado, S. H. (2011). Effects of maturity stage and storage on cactus berry (Myrtillocactus geometrizans) phenolics, vitamin C, betalains and their antioxidant properties. Food Chemistry, 129(4), 1744-1750. https://doi.org/10.1016/j.foodchem.2011.06.042

Larrauri, J. A., Rupérez, P., Borroto, B., \& Saura-Calixto, F. (1996). Mango Peels as a New Tropical Fibre: Preparation and Characterization. LWT-Food Science and Technology, 29(8), 729-733. https://doi.org/10.1006/fstl.1996.0113

Liaotrakoon, W., De Clercq, N., Lewille, B., \& Dewettinck, K. (2012). Physicochemical properties, glass transition state diagram and colour stability of pulp and peel of two dragon fruit varieties (Hylocereus spp.) as affected by freeze-drying. International Food Research Journal, 19(2), 743-750.

Mounir, S., Allaf, T., Berka, B., Hassani, A., \& Allaf, K. (2014). Instant Controlled Pressure Drop technology: From a new fundamental approach of instantaneous transitory thermodynamics to large industrial applications on high performance-high controlled quality unit operations. Comptes Rendus Chimie, 17(3), 261-267. https://doi.org/10.1016/j.crci.2013.10.019

Nilsson, T. (1970). Studies into the Pigments in Beetroot (Beta vulgaris L. ssp. vulgaris var. rubra L.). Lantbrukshogskolans Annaler, 36, 179-219.

Pavlov, A., Kovatcheva, P., Georgiev, V., Koleva, I., \& Ilieva, M. (2002). Biosynthesis and Radical Scavenging Activity of Betalains during the Cultivation of Red Beet (Beta vulgaris) Hairy Root Cultures. Zeitschrift für Naturforschung C, 57(7-8), 640-644. https://doi.org/10.1515/znc-2002-7-816

Perez-Gonzalez, S. (1995, July 30- August 3, 1995). Agroecological study and determination of yield potential of garambullo (Myrtillocactus geometrizans) in Queretaro, Mexico. Paper presented at the Annual Meeting of the American Society for Horticultural Science, Montréal, Québec, Canada.

Pérez-Jiménez, J., \& Torres, J. L. s. (2011). Analysis of Nonextractable Phenolic Compounds in Foods: The Current State of the Art. Journal of Agricultural and Food Chemistry, 59(24), 12713-12724. https://doi.org/10.1021/jf203372w

Prosky, L., Asp, N.-G., Schweizer, T., DeVries, J., \& Furda, I. (1988). Determination of Insoluble, Soluble, and Total Dietary Fiber in Foods and Food Products: Interlaboratory Study. Journal of AOAC International, 71(5), 1017-1023.

Ratti, C. (2009). Novel Food Dryers and Future Perspectives. In C. Ratti (Ed.), Advances in Food Dehydration (pp. 447-462). USA: CRC Press.

Re, R., Pellegrini, N., Proteggente, A., Pannala, A., Yang, M., \& Rice-Evans, C. (1999). Antioxidant Activity Applying an Improved ABTS Radical Cation Decolorization Assay. Free Radical Biology and Medicine, 26(9), 1231-1237. https://doi.org/10.1016/S0891-5849(98)00315-3

Reynoso-Camacho, R., Martinez-Samayoa, P., Ramos-Gomez, M., Guzmán, H., \& Salgado, L. M. (2015). Antidiabetic and Renal Protective Properties of Berrycactus Fruit (Myrtillocactus geometrizans). Journal of Medicinal Food, OO(0), 1-7. https://doi.org/10.1089/jmf.2013.0164

Saura-Calixto, F. (1998). Antioxidant Dietary Fiber Product: A New Concept and a Potential Food Ingredient. Journal of Agricultural and Food Chemistry, 46(10), 4303-4306. https://doi.org/10.1021/jf9803841

Singleton, V. L., Orthofer, R., \& Lamuela-Raventos, R. M. (1999). Analysis of Total Phenols and Other Oxidation Substrates and Antioxidants by Means of Folin-Ciocalteu Reagent. Methods in Enzymology, 299, 152-178. https://doi.org/10.1016/S0076-6879(99)99017-1

St. George, S. D., \& Cenkowski, S. (2009). Dehydration Processes for Nutraceuticals and Functional Foods. In C. Ratti (Ed.), Advances in Food Dehydration (pp. 285-314). USA: CRC Press.

Tavares, L., Carrilho, D., Tyagi, M., Barata, D., Serra, A. T., Duarte, C. M. M., Duarte, R. O., Feliciano, R. P., Bronze, M. R., \& Chicau, P. (2010). Antioxidant Capacity of Macaronesian Traditional Medicinal Plants. Molecules, 15(4), 2576-2592. https://doi.org/10.3390/molecules15042576

Tesoriere, L., Butera, D., Pintaudi, A. M., Allegra, M., \& Livrea, M. A. (2004). Supplementation with cactus pear (Opuntia ficus-indica) fruit decreases oxidative stress in healthy humans: a comparative study with vitamin C. The American Journal of Clinical Nutrition, 80(2), 391-395. 
Viloria-Matos, A., Corbelli-Moreno, D., Moreno-Álvarez, M., \& Belén, D. (2002). Estabilidad de betalaínas en pulpa de tuna (Opuntia boldinghii Br. et R.) sometidas a un proceso de liofilización. Revista de la Facultad de Agronomía de la Universidad de Zulia, 324-331.

Wu, L., Hsu, H., Chen, Y., Chiu, C., Lin, Y., \& Ho, J. (2006). Antioxidant and antiproliferative activities of red pitaya. Food Chemistry, 95(2), 319-327. https://doi.org/10.1016/j.foodchem.2005.01.002

\section{Copyrights}

Copyright for this article is retained by the author(s), with first publication rights granted to the journal.

This is an open-access article distributed under the terms and conditions of the Creative Commons Attribution license (http://creativecommons.org/licenses/by/4.0/). 